\title{
全生育期鉴定笁选耐盐碱花生品种
}

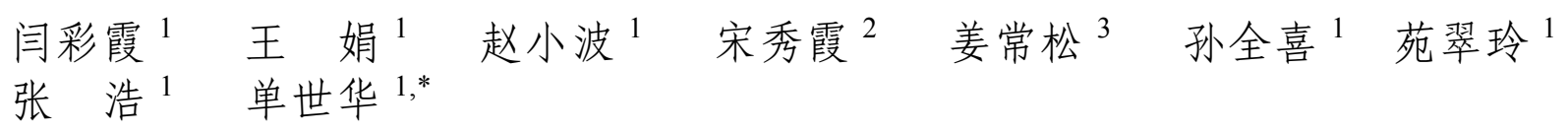

${ }^{1}$ 山东省花生研究所, 山东青岛 $266100 ;{ }^{2}$ 菏泽市牡丹区农业农村局, 山东菏泽 $274000 ;{ }^{3}$ 海阳市农业技术推广中心, 山东烟台 265100

摘 要: 为改善黄河三角洲滨海盐碱地种植结构, 扩大花生种植面积, 本研究以 22 个育成的花生品种(系)为材料, 测定 了全生育期 9 个性状指标, 利用方差分析、相关分析、聚类分析等进行耐盐碱鉴定及耐盐碱指标笁选。结果表明, 盐碱 胁迫显著降低花生成苗率, 明显抑制花生的生长发育和产量形成, 不同品种(系)间在 9 个鉴定指标上存在较大差异。相 对单株产量和相对小区产量均与相对地上部干重、相对主茎高、相对侧枝长呈显著正相关, 相对小区产量与相对成苗率、 相对地下部干重、相对单株产量显著正相关。全部材料可划分为 4 个耐盐碱级别, 其中高度耐盐碱 7 份(I 级)、较耐盐 碱 11 份(II 级)、盐碱胁迫敏感 3 份(III 级)、高度敏感 1 份(IV 级)。篮选出花育 9307、花育 9312、花育 9313、6P03、花 育 9305 及花育 6303 等适于盐碱地种植的高产品种(系)。本研究表明, 相对地上部干重、相对主茎高、相对成苗率、相 对单株产量、相对侧枝长、相对地下部干重可作为简单、直观的花生耐盐碱鉴定指标。

关键词：花生; 全生育期；耐盐碱；高产；鉴定

\section{Identification and screening of saline-alkali tolerant peanut cultivars during whole growth stage}

\author{
YAN Cai-Xia ${ }^{1}$, WANG Juan ${ }^{1}$, ZHAO Xiao-Bo ${ }^{1}$, SONG Xiu-Xia ${ }^{2}$, JIANG Chang-Song, SUN Quan-Xi ${ }^{1}$, \\ YUAN Cui-Ling ${ }^{1}$, ZHANG Hao ${ }^{1}$, and SHAN Shi-Hua ${ }^{1, *}$ \\ ${ }^{1}$ Shandong Peanut Research Institute, Qingdao 266100, Shandong, China; ${ }^{2}$ Agricultural and Rural Bureau of Mudan District, Heze 274000, \\ Shandong, China; ${ }^{3}$ Haiyang Agricultural Technology Extension Center, Yantai 265100, Shandong, China
}

\begin{abstract}
In order to improve the planting structure of coastal saline-alkali land and enlarge the growing area of peanut in the Yellow River Delta. A total of 22 peanut elite cultivars were tested in saline-alkali area of Dongying in 2016 and 2017. Nine trait indices were separately investigated for five randomly selected individuals during whole growth stage. Variance analysis, correlation analysis and clustering analysis were used to evaluate the saline-alkali tolerance of the materials and to screen saline-alkali tolerant indices. Variance analysis showed that the seedling rates of all cultivars had an obvious decrease compared with those of the control. The growth, development and yield formation were essentially inhibited by saline-alkali stress. There were great differences among tested materials based on nine identification indices. Correlation analysis indicated that RYP and RPY had a significantly positive correlation with RSDW, RMSH and RBL. Additionally, RPY was also obviously related to RSR, RRDW, and RYP. Based on the results of clustering analysis, tested materials were divided into four saline-alkali tolerance grades, in which seven belonged to high tolerant grade I, 11 to tolerant grade II, 3 to susceptible grade III and 1 to highly susceptible grade IV. Huayu 9307, Huayu 9312, Huayu 9313, 6P03, Huayu 9305 and Huayu 6303 could be widely grown in the coastal saline-alkali area as high yield cultivars. In conclusion, the results suggested that RSDW, RMSH, RSR, RYP, RBL, and RRDW could be taken as simple and intuitive indices in the identification of saline-alkali tolerant peanut genotypes.
\end{abstract}

本研究由泰山学者特聘专家(ts201712080), 农业科研杰出人才及其创新团队培养(13190194), 山东省现代农业产业技术体系 (SDAIT-04-02)和山东省农业科学院农业科技创新工程 (CXGC2016A01)资助。

This study was supported by the Taishan Scholars Project (ts201712080), the Outstanding Talents and Innovation Team in Agricultural Research (13190194), the Shandong Agriculture Research System (SDAIT-04-02), and the Agricultural Science and Technological Innovation Project of Shandong Academy of Agricultural Science (CXGC2016A01).

*通信作者(Corresponding author): 单世华, E-mail: shansh1971@163.com

第一作者联系方式: E-mail: cxyan335@sina.com

Received (收稿日期): 2020-05-14; Accepted (接受日期): 2020-09-13; Published online (网络出版日期): 2020-10-10.

URL: https://kns.cnki.net/kcms/detail/11.1809.S.20201010.1037.002.html 
Keywords: peanut; whole growth period; saline-alkali tolerance; high-yield; identification

山东鲁北滨海盐碱地主要分布在渤海湾南岸, 即德 州、滨州、东营和潍坊一带，其中，黄河三角洲盐渍化土 地面积约为 60.5 万公顷, 全盐含量为 $0.1 \% \sim 0.4 \%$ 的轻度 盐碱地为 34.85 万公顷, 严重制约着当地农业的可持续发 展 ${ }^{[1]}$ 。花生(Arachis hypogaea L.) 是中国的四大油料作物之 一, 种子含油量 $45 \% \sim 50 \%$, 种植面积约为油菜籽或大豆 的 $65 \%$, 总产却稳居第一, 单产是油菜和大豆的近 2 倍 (http://zzys.agri.gov.cn/nongqing.aspx)。因此, 花生单位面 积产油量高, 生产价值和市场价值较大。花生为中等耐盐 作物, 适应性强、增产潜力大, 适宜与粮食作物或棉花轮 作。因此, 亟需篮选耐盐碱、高产的花生品种(系), 以加 快盐碱地的利用和改良, 促进黄河三角洲种植业结构调 整, 扩大花生种植面积, 提高我国食用油脂的自给率 ${ }^{[2]}$ 。

花生种子要经过吸水膨胀萌发、胚根伸长、侧根生长 等阶段发育成幼苗, 盐胁迫对这一生长发育过程有显著 的影响。前人研究发现, 盐胁迫会逐渐降低花生种子的发 芽率和发芽势, 显著抑制其萌发, 延长出苗时间 ${ }^{[3-4]}$, 降 低花生幼根的根长、根粗和根重, 明显抑制幼苗的相对苗 高、相对地上部鲜重等 ${ }^{[5-6]}$ 。芽期耐盐性与其他时期耐盐 性无明显关联 ${ }^{[7]}$, 盐胁迫对花生成株的影响主要表现为 叶片失绿、黄化, 最后干枯、脱落, 严重时能导致整株 死亡 ${ }^{[8-10]}$ 。张智猛等 ${ }^{[11]}$ 采用隶属函数值法对 200 个花生品 种进行耐盐性评价发现, 随着盐胁迫浓度增加, 植株形态 建成抑制加重, 株高降低、物质积累减少, 植株含水量明 显下降, 果针数减少, 果针重和荚果重均下降 ${ }^{[12]}$, 并确定 了花生耐盐品种盆栽鉴选的适宜 $\mathrm{NaCl}$ 浓度为 $4.5 \%{ }^{[13]}$ 。

盐碱地所含致害盐类除了以 $\mathrm{NaCl}$ 和 $\mathrm{MgCl}_{2}$ 为主的盐 土以外, 还有以 $\mathrm{Na}_{2} \mathrm{CO}_{3}$ 为主的碱土, 盐土和碱土往往并 存, 而目前的研究多以耐盐性为主, 与实际的盐碱胁迫不

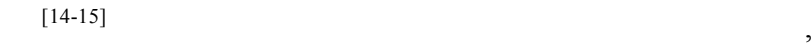
多以相对发芽率、胚根长度、主茎高、侧枝长、生物量等 指标作为选择依据 ${ }^{[16-17]}$, 缺乏最为关键的产量指标, 不能 系统评价花生品种整个生育期的耐盐碱差异。本研究以黄
河三角洲滨海盐碱地为试验田, 研究其对 22 个花生品种(系) 成苗率、农艺性状、产量性状等的影响, 系统而全面地评 价花生不同基因型间的耐盐碱性差异, 篮选耐盐碱的高产 品种, 以期为花生在盐碱地的生产利用提供理论依据。

\section{1 材料与方法}

\section{1 试验点概况}

试验于 2016-2017 年在山东省农业科学院东营黄河 三角洲试验示范基地 $\left(37^{\circ} 31^{\prime} \mathrm{N}, 118^{\circ} 58^{\prime} \mathrm{E}\right)$ 进行, 距渤海岸 直线距离约 $30 \mathrm{~km}$, 土壤类型为典型的盐渍化潮土。2016 年 5 月至 9 月总降雨量为 $395.4 \mathrm{~mm}, 7$ 月中旬至 8 月中旬 雨量较大, 适逢花生需水量最高的结荚期, 墑情较好, 耕 作层土壤绝对含水量为 $16.48 \%$ 。 8 月中旬至 9 月中旬雨量 逐渐减少, 饱果期花生的需水量也降低, 耕作层土壤绝对 含水量为 $12.91 \% 。 2017$ 年 5 月至 9 月总降雨量 $378.8 \mathrm{~mm}$, 结荚期墒情好, 耕作层土壤绝对含水量为 $18.12 \%$, 饱果 期土壤绝对含水量为 $11.73 \%$ 。试验期间气象数据由广饶 县气象局提供(图 1)。于结荚期(pod-setting stage)和饱果成 熟期(pod-filling stage, 简称饱果期)按对角线法取 0 20 $\mathrm{cm}$ 土样, 其基础理化性质见表 1 , 并以小清河以南试验点 正常地块作对照。试验地 $\mathrm{pH}$ 和含盐量较对照明显偏高, 有效磷含量很低。含盐量随季节变化下降, 从 $2.253 \%$ 降 至 2.093\%o, 约为普通土壤含盐量的 2.0 2.5 倍(表 1)。



图 $12016-2017$ 年试验进行期间广饶的月降雨量

Fig. 1 Monthly precipitation at the experimental site in Guangrao from 2016 to 2017

表 1 试验地及正常地块土壤的理化性质

Table 1 Basic physical and chemical properties of tested soils and normal soils of 0-20 cm

\begin{tabular}{|c|c|c|c|}
\hline \multirow{2}{*}{$\begin{array}{l}\text { 指标 } \\
\text { Index }\end{array}$} & \multicolumn{2}{|c|}{ 试验田 Experimental field } & \multirow{2}{*}{$\begin{array}{c}\text { 正常地块 } \\
\text { Normal field }\end{array}$} \\
\hline & 结荚期 Pod-setting stage & 饱果期 Pod-filling stage & \\
\hline $\mathrm{pH}$ & 8.9 & 8.5 & 6.6 \\
\hline 有机质 Organic matter (\%) & 0.97 & 1.34 & 1.19 \\
\hline 全氮 Total N (\%) & 0.073 & 0.100 & 0.081 \\
\hline 全钾 Total K (\%) & 1.99 & 2.07 & 2.12 \\
\hline 全磷 Total P $\left(\mathrm{mg} \mathrm{kg}^{-1}\right)$ & 682 & 772 & 975 \\
\hline 有效磷 Olsen-P (mg kg $\left.{ }^{-1}\right)$ & 6.9 & 5.5 & 55.9 \\
\hline 速效钾 Available $\mathrm{K}\left(\mathrm{mg} \mathrm{kg}^{-1}\right)$ & 363.5 & 540.6 & 310.1 \\
\hline 碱解氮 Alkali-hydrolysable N (mg kg $\left.{ }^{-1}\right)$ & 137.3 & 69.5 & 107.9 \\
\hline 含盐量 Salinity (\%o) & 2.253 & 2.093 & 1.093 \\
\hline
\end{tabular}




\section{2 供试材料与试验设计}

选取 22 个高产花生品种(系)作为试验材料, 其中大 果花生 14 个, 小果花生 8 个, 全部为本课题组选育而成, 其亲本来源、正常栽培条件下百果重和品种类型如表 2 所示。由于试验地为自然撂荒地, 播前大水漫灌 1 次, 以 降低表层土壤含量盐，旋耕 2 次，使土壤盐分更加均匀。
播种前施总养分 $\geq 45 \%$ 的高效复合肥(含 $14 \% \mathrm{~N}$ 、 $16 \%$ $\left.\mathrm{P}_{2} \mathrm{O}_{5} 、 15 \% \mathrm{~K}_{2} \mathrm{O}\right) 225 \mathrm{~kg} \mathrm{hm}^{-2}$ 作为基肥, 翻入 $15 \mathrm{~cm}$ 下耕 作层。采用完全随机区组试验设计, 起垄覆膜栽培, 垄长 $5 \mathrm{~m}$, 垄宽 $0.85 \mathrm{~m}$, 每垄 2 行, 行株距 $40 \mathrm{~cm} \times 17 \mathrm{~cm}$, 小区 面积约 $15 \mathrm{~m}^{2}$, 单粒播, 深度为 $3 \mathrm{~cm}, 3$ 次重复。 5 月 6 日 播种, 9 月 15 日收获, 田间管理措施同常规。

表 2 供试的 22 个花生品种(系)的亲本来源、品种类型及在正常栽培条件下的百果重

Table 2 Parents, variety type and 100-pod weight under normal soil conditions of 22 peanut accessions used in this study

\begin{tabular}{|c|c|c|c|}
\hline $\begin{array}{c}\text { 品种(系) } \\
\text { Cultivar (line) } \\
\end{array}$ & $\begin{array}{c}\text { 亲本 } \\
\text { Parents } \\
\end{array}$ & $\begin{array}{c}\text { 百果重 } \\
\text { 100-pod weight (g) }\end{array}$ & $\begin{array}{c}\text { 品种类型 } \\
\text { Variety type } \\
\end{array}$ \\
\hline $6 \mathrm{P} 03$ & 花 $85 \times$ 营山大花生 Hua $85 \times$ Yingshan peanut & 270.2 & 大果 Big-pod \\
\hline 6Р09 & 花 17×鲁花 11 Hua $17 \times$ Luhua 11 & 279.3 & 大果 Big-pod \\
\hline 花育 6301 Huayu 6301 & 花育 $23 \times \mathrm{J} 11$ Huayu $23 \times \mathrm{J} 11$ & 150.6 & 小果 Small-pod \\
\hline 花育 6303 Huayu 6303 & 赣花 1 号×鲁花 15 Ganhua $1 \times$ Luhua 15 & 260.5 & 小果 Small-pod \\
\hline 花育 6304 Huayu 6304 & 乡香 $\times$ D16 Xiangxiang $\times D 16$ & 215.8 & 小果 Small-pod \\
\hline 花育 6306 Huayu 6306 & 花育 $20 \times J 11$ Huayu $20 \times J 11$ & 238.5 & 小果 Small-pod \\
\hline 花育 6307 Huayu 6307 & 赣花 1 号×海花 1 号 Ganhua $1 \times$ Haihua 1 & 210.9 & 小果 Small-pod \\
\hline 花育 6312 Huayu 6312 & 花 17×赣花 1 号 Hua 17×Ganhua 1 & 207.8 & 小果 Small-pod \\
\hline 花育 6314 Huayu 6314 & 鲁花 $15 \times J 11$ Luhua $15 \times J 11$ & 248.0 & 小果 Small-pod \\
\hline 花育 71 Huayu 71 & 乡香×闽花 10 号 Xiangxiang $\times$ Minhua 10 & 290.6 & 大果 Big-pod \\
\hline 花育 9301 Huayu 9301 & 海花 1 号×XW87 Haihua $1 \times X W 87$ & 298.5 & 大果 Big-pod \\
\hline 花育 9302 Huayu 9302 & 花 98×罗江鸡窝 Hua 98×Luojiangjiwo & 283.2 & 大果 Big-pod \\
\hline 花育 9303 Huayu 9303 & 鲁花 $15 \times$ 赣花 1 号 Luhua $15 \times$ Ganhua 1 & 258.3 & 小果 Small-pod \\
\hline 花育 9305 Huayu 9305 & 花 98×鲁花 11 Hua 98×Luhua 11 & 282.7 & 大果 Big-pod \\
\hline 花育 9306 Huayu 9306 & 白沙 $1016 \times X W 84$ Baisha $1016 \times X W 84$ & 280.3 & 大果 Big-pod \\
\hline 花育 9307 Huayu 9307 & 费县爬蔓×花育 22 Feixianpaman×Huayu 22 & 276.3 & 大果 Big-pod \\
\hline 花育 9308 Huayu 9308 & 花 $98 \times$ 粤油 551 Hua $98 \times$ Yueyou 551 & 282.6 & 大果 Big-pod \\
\hline 花育 9309 Huayu 9309 & 花育 $19 \times$ 乡香 Huayu 19×Xiangxiang & 279.5 & 大果 Big-pod \\
\hline 花育 9310 Huayu 9310 & 8328-12×五莲大粒 $8328-12 \times$ Wuliandali & 284.3 & 大果 Big-pod \\
\hline 花育 9311 Huayu 9311 & 蓬莱半蔓 $\times$ NcAc1 8016 Penglaibanman $\times$ NcAc1 8016 & 277.1 & 大果 Big-pod \\
\hline 花育 9312 Huayu 9312 & 花育 $23 \times$ 花 17 Huayu $23 \times$ Hua 17 & 302.6 & 大果 Big-pod \\
\hline 花育 9313 Huayu 9313 & 花育 $22 \times C 76-16$ Huayu $22 \times C 76-16$ & 278.9 & 大果 Big-pod \\
\hline
\end{tabular}

\section{3 测定内容及方法}

播种后 $30 \mathrm{~d}$ 统计不同花生品种(系)的成苗情况，成苗 率=成苗数/播种粒数 $\times 100 \%$ 。于结荚期(取样时间为 8 月 10 日)采集样品，避开地头和空苗段，每个品种(系)分别 选取 5 株生长一致、比较典型的植株，保持根系完整并冲 洗干净; 根据《花生栽培观察记载技术规范》中的有关方 法 $^{[18]}$, 测定主茎高、侧枝长; 按地上部、地下部分开, 先 于 $105^{\circ} \mathrm{C}$ 下杀青 $1.0 \mathrm{~h}$, 再于 $80^{\circ} \mathrm{C}$ 下烘至恒重并称其干重。 于饱果期(取样时间为 9 月 5 日)再次采样, 摘取英果晾晒至 含水量低于 $10 \%$, 测量单株产量、百果重、百仁重。收获 (9月 15 日)后测定小区产量(plot yield, PY, 单位 $\mathrm{kg} \mathrm{hm}^{-2}$ )。

\section{4 耐盐碱指数与数据分析}

取各性状指标 2 年测定值的平均值, 以正常生长环境 下性状均值为对照, 将各指标转化为耐盐碱指数: 耐盐碱 指数 $=$ 盐胁迫值/对照值。各指标耐盐碱指数分别为相对成 苗率(relative seedling rate, RSR)、相对主茎高(relative main stem height, RMSH)、相对侧枝长(relative branch length, RBL)、相对地上部干重(relative shoot dry weight, RSDW)、相对地下部干重(relative root dry weight, RRDW)、相对单株产量(relative yield per plant, RYP)、相 对百果重(relative 100-pod weight, 100-RPW)、相对百仁重 (relative 100-seed weight，100-RSW)及相对小区产量 
(relative plot yield, RPY)。用 Microsoft Excel 2010 处理试 验数据并绘制图表, 利用 SPSS19.0 软件进行显著性检验、 相关性分析及聚类分析。

\section{2 结果与分析}

\section{1 盐碱胁迫对花生成苗率的影响}

萌发期和幼苗期的耐盐碱能力决定了花生种子的成 苗率, 并最终影响花生的产量。由表 3 可知, 盐碱胁迫严 重抑制花生成苗, 22 个品种(系)的成苗率比对照降低 $12.0 \% \sim 50.3 \%$, 说明在盐碱胁迫条件下花生幼苗的生长发 育受到了严重的影响。不同基因型间存在较大差异, 花育 9307 抗性最好, 相对成苗率为 0.88 , 与成苗率较低的花育 9301、花育 9308、6P09、花育 71 、花育 9302 和花育 9310 差异显著; 其次为花育 6303、花育 6307、花育 9305、花 育 9306、6P03、花育 9312、花育 9303 和花育 9313，相对
成苗率 $\geq 0.75$; 这些品种均为萌发期和苗期耐盐碱花生基 因型。抗性最差的为花育 9301 和花育 9308 , 相对成苗率 约为 0.5 , 即有过半的种子未出苗或幼苗期死亡。

\section{2 盐碱胁迫对花生农艺性状的影响}

从表 4 可知, 盐碱胁迫明显抑制花生地下部的生长 发育, 对地上部影响则存在较大的基因型差异。22 个品 种(系)的相对主茎高和相对侧枝长变幅不同, 分别在 $0.637 \sim 1.297$ 和 $0.620 \sim 1.203$ 之间，花育 9312、花育 9307、 花育 6314 等 13 个品种(系)的 2 个指标值均大于 0.95 , 且大部分高于对照，其中的花育 9313、花育 6303、 6P03、花育 9307、花育 9312、花育 9305、花育 9310 相对地上部干重均高于 0.9 , 且品种间在 $5 \%$ 水平无显 著差异。相对地下部干重在 $0.210 \sim 0.933$ 之间, 花育 9307、花育 9313、花育 9312 等 8 个品种均大于 0.7 , 且 差异不明显。

表 3 盐碱胁迫对 22 个花生品种(系)成苗率的影响

Table 3 Effects of saline-alkali stress on the seedling rate in 22 peanut cultivars

\begin{tabular}{|c|c|c|c|}
\hline $\begin{array}{c}\text { 品种(系) } \\
\text { Cultivar (line) }\end{array}$ & $\begin{array}{c}\text { 相对成苗率 } \\
\text { RSR }\end{array}$ & $\begin{array}{c}\text { 品种(系) } \\
\text { Cultivar (line) }\end{array}$ & $\begin{array}{c}\text { 相对成苗率 } \\
\text { RSR }\end{array}$ \\
\hline 6P03 & $0.81 \mathrm{ab}$ & 花育 9302 Huayu 9302 & $0.593 \mathrm{bcd}$ \\
\hline 6Р09 & $0.587 \mathrm{bcd}$ & 花育 9303 Huayu 9303 & $0.757 \mathrm{abc}$ \\
\hline 花育 6301 Huayu 6301 & $0.703 \mathrm{abcd}$ & 花育 9305 Huayu 9305 & $0.823 \mathrm{ab}$ \\
\hline 花育 6303 Huayu 6303 & $0.837 \mathrm{ab}$ & 花育 9306 Huayu 9306 & $0.81 \mathrm{ab}$ \\
\hline 花育 6304 Huayu 6304 & $0.687 \mathrm{abcd}$ & 花育 9307 Huayu 9307 & $0.88 \mathrm{a}$ \\
\hline 花育 6306 Huayu 6306 & $0.737 \mathrm{abcd}$ & 花育 9308 Huayu 9308 & $0.51 \mathrm{~cd}$ \\
\hline 花育 6307 Huayu 6307 & $0.83 \mathrm{ab}$ & 花育 9309 Huayu 9309 & $0.743 \mathrm{abc}$ \\
\hline 花育 6312 Huayu 6312 & $0.643 \mathrm{abcd}$ & 花育 9310 Huayu 9310 & $0.623 \mathrm{bcd}$ \\
\hline 花育 6314 Huayu 6314 & $0.703 \mathrm{abcd}$ & 花育 9311 Huayu 9311 & $0.72 \mathrm{abcd}$ \\
\hline 花育 71 Huayu 71 & $0.59 \mathrm{bcd}$ & 花育 9312 Huayu 9312 & $0.777 \mathrm{ab}$ \\
\hline 花育 9301 Huayu 9301 & $0.497 \mathrm{~d}$ & 花育 9313 Huayu 9313 & $0.747 \mathrm{abc}$ \\
\hline
\end{tabular}

同列不同小写字母表示在 0.05 水平上差异显著。

RSR: relative seedling rate. Values followed by different lowercase letters in the same column indicate significant differences among cultivars at the 0.05 probability level.

表 4 盐碱胁迫对 22 个花生品种(系)农艺性状和产量性状的影响

Table 4 Effects of saline-alkali stress on peanut agronomic traits and yield traits in 22 peanut cultivars

\begin{tabular}{|c|c|c|c|c|c|c|c|}
\hline $\begin{array}{c}\text { 品种(系) } \\
\text { Cultivar (line) }\end{array}$ & $\begin{array}{c}\text { 相对主茎高 } \\
\text { RMSH }\end{array}$ & $\begin{array}{c}\text { 相对侧枝长 } \\
\text { RBL }\end{array}$ & $\begin{array}{c}\text { 相对地上部干重 } \\
\text { RSDW }\end{array}$ & $\begin{array}{c}\text { 相对地下部干重 } \\
\text { RRDW }\end{array}$ & $\begin{array}{c}\text { 相对单株产量 } \\
\text { RYP }\end{array}$ & $\begin{array}{c}\text { 相对百果重 } \\
100-R P W\end{array}$ & $\begin{array}{c}\text { 相对百仁重 } \\
100-R S W\end{array}$ \\
\hline $6 \mathrm{P} 03$ & $1.013 \mathrm{defg}$ & $1 \mathrm{bcd}$ & $0.973 \mathrm{abc}$ & 0.663 bcde & $0.947 \mathrm{a}$ & $0.933 \mathrm{abc}$ & $0.937 \mathrm{ab}$ \\
\hline $6 \mathrm{P} 09$ & 0.84 ghij & $0.767 \mathrm{fgh}$ & $0.83 \mathrm{cdef}$ & $0.747 \mathrm{abcd}$ & $0.807 \mathrm{abc}$ & $0.817 \mathrm{def}$ & $0.873 \mathrm{bc}$ \\
\hline 花育 6301 Huayu 6301 & $1.107 \mathrm{bcd}$ & 0.923 cde & $0.8 \mathrm{cdef}$ & $0.897 \mathrm{a}$ & $0.833 \mathrm{abc}$ & $0.713 \mathrm{gh}$ & $0.853 \mathrm{bc}$ \\
\hline 花育 6303 Huayu 6303 & $1.033 \mathrm{cdef}$ & 0.96 bcde & $1.023 \mathrm{ab}$ & $0.523 \mathrm{efgh}$ & $0.97 \mathrm{a}$ & $0.95 \mathrm{ab}$ & $0.983 \mathrm{a}$ \\
\hline 花育 6304 Huayu 6304 & 0.983 defgh & $1.08 \mathrm{abc}$ & $0.787 \mathrm{def}$ & $0.837 \mathrm{ab}$ & $0.837 \mathrm{abc}$ & $0.783 \mathrm{efg}$ & $0.86 \mathrm{bc}$ \\
\hline 花育 6306 Huayu 6306 & $1.117 \mathrm{bcd}$ & $1.123 \mathrm{ab}$ & 0.737 ef & $0.423 \mathrm{fgh}$ & $0.797 \mathrm{abc}$ & $0.913 \mathrm{abc}$ & $0.913 \mathrm{ab}$ \\
\hline 花育 6307 Huayu 6307 & 0.84 ghij & $0.863 \mathrm{def}$ & 0.77 ef & $0.403 \mathrm{gh}$ & $0.8 \mathrm{abc}$ & $0.653 \mathrm{~h}$ & $0.757 \mathrm{~d}$ \\
\hline 花育 6312 Huayu 6312 & $0.733 \mathrm{ijk}$ & $0.77 \mathrm{fgh}$ & $0.76 \mathrm{ef}$ & 0.643 cde & $0.79 \mathrm{abc}$ & 0.787 efg & $0.86 \mathrm{bc}$ \\
\hline 花育 6314 Huayu 6314 & $1.2 \mathrm{abc}$ & $1.107 \mathrm{ab}$ & $0.747 \mathrm{ef}$ & 0.7 bcde & $0.707 \mathrm{abc}$ & $0.907 \mathrm{abc}$ & $0.917 \mathrm{ab}$ \\
\hline 花育 71 Huayu 71 & 0.927 efgh & 0.963 bcde & $0.79 \mathrm{def}$ & 0.527 efgh & $0.763 \mathrm{abc}$ & $0.893 \mathrm{abcd}$ & $0.913 \mathrm{ab}$ \\
\hline
\end{tabular}


(续表 4)

\begin{tabular}{|c|c|c|c|c|c|c|c|}
\hline $\begin{array}{c}\text { 品种(系) } \\
\text { Cultivar (line) } \\
\end{array}$ & $\begin{array}{c}\text { 相对主茎高 } \\
\text { RMSH } \\
\end{array}$ & $\begin{array}{c}\text { 相对侧枝长 } \\
\text { RBL } \\
\end{array}$ & $\begin{array}{c}\text { 相对地上部干重 } \\
\text { RSDW } \\
\end{array}$ & $\begin{array}{c}\text { 相对地下部干重 } \\
\text { RRDW } \\
\end{array}$ & $\begin{array}{c}\text { 相对单株产量 } \\
\text { RYP } \\
\end{array}$ & $\begin{array}{c}\text { 相对百果重 } \\
100-R P W \\
\end{array}$ & $\begin{array}{c}\text { 相对百仁重 } \\
100-R S W \\
\end{array}$ \\
\hline 花育 9301 Huayu 9301 & $0.81 \mathrm{hij}$ & $0.62 \mathrm{~h}$ & $0.47 \mathrm{~g}$ & $0.21 \mathrm{i}$ & $0.73 \mathrm{abc}$ & $0.897 \mathrm{abc}$ & $0.937 \mathrm{ab}$ \\
\hline 花育 9302 Huayu 9302 & 0.897 fghi & $0.93 \mathrm{cde}$ & $0.67 \mathrm{f}$ & $0.743 \mathrm{abcd}$ & $0.823 \mathrm{abc}$ & $0.867 \mathrm{~cd}$ & $0.88 \mathrm{bc}$ \\
\hline 花育 9303 Huayu 9303 & $0.637 \mathrm{k}$ & $0.697 \mathrm{gh}$ & $0.76 \mathrm{ef}$ & $0.53 \mathrm{efgh}$ & $0.573 \mathrm{c}$ & $0.817 \mathrm{def}$ & $0.9 \mathrm{abc}$ \\
\hline 花育 9305 Huayu 9305 & 0.993 defg & $1.007 \mathrm{bcd}$ & $0.957 \mathrm{abcd}$ & $0.573 \mathrm{defg}$ & $0.86 \mathrm{ab}$ & $0.923 \mathrm{abc}$ & $0.903 \mathrm{abc}$ \\
\hline 花育 9306 Huayu 9306 & $0.69 \mathrm{jk}$ & $0.657 \mathrm{~h}$ & 0.857 bcdef & $0.443 \mathrm{fgh}$ & $0.64 \mathrm{bc}$ & $0.76 \mathrm{fg}$ & $0.817 \mathrm{~cd}$ \\
\hline 花育 9307 Huayu 9307 & $1.227 \mathrm{ab}$ & $1.073 \mathrm{abc}$ & $0.96 \mathrm{abcd}$ & $0.933 \mathrm{a}$ & $0.85 \mathrm{abc}$ & $0.877 \mathrm{bcd}$ & $0.87 \mathrm{bc}$ \\
\hline 花育 9308 Huayu 9308 & 0.813 hij & 0.833 efg & $0.723 \mathrm{f}$ & $0.363 \mathrm{hi}$ & $0.807 \mathrm{abc}$ & $0.913 \mathrm{abc}$ & $0.89 \mathrm{abc}$ \\
\hline 花育 9309 Huayu 9309 & 1.093 bcde & $1.057 \mathrm{abc}$ & $0.777 \mathrm{def}$ & $0.61 \mathrm{def}$ & $0.733 \mathrm{abc}$ & $0.867 \mathrm{~cd}$ & $0.93 \mathrm{ab}$ \\
\hline 花育 9310 Huayu 9310 & 1.097 bcde & $1.087 \mathrm{abc}$ & 0.92 abcde & $0.803 \mathrm{abc}$ & $0.913 \mathrm{ab}$ & $0.93 \mathrm{abc}$ & $0.923 \mathrm{ab}$ \\
\hline 花育 9311 Huayu 9311 & $1.11 \mathrm{bcd}$ & $1.067 \mathrm{abc}$ & $0.79 \mathrm{def}$ & $0.437 \mathrm{fgh}$ & $0.787 \mathrm{abc}$ & 0.857 cde & $0.933 \mathrm{ab}$ \\
\hline 花育 9312 Huayu 9312 & $1.297 \mathrm{a}$ & $1.203 \mathrm{a}$ & $0.957 \mathrm{abcd}$ & $0.917 \mathrm{a}$ & $0.877 \mathrm{ab}$ & $0.97 \mathrm{a}$ & $0.947 \mathrm{ab}$ \\
\hline 花育 9313 Huayu 9313 & $1.133 \mathrm{abcd}$ & 0.97 bcde & $1.063 \mathrm{a}$ & $0.923 \mathrm{a}$ & $0.877 \mathrm{ab}$ & $0.907 \mathrm{abc}$ & $0.89 \mathrm{abc}$ \\
\hline
\end{tabular}

同列不同小写字母表示在 0.05 水平上差异显著。

RMSH: relative main stem height; RBL: relative branch length; RSDW: relative shoot dry weight; RRDW: relative root dry weight; RYP: relative yield per pant; 100-RPW: relative 100-pod weight; 100-RSW: relative 100-seed weight. Values followed by different lowercase letters in the same column indicate significant differences among cultivars at the 0.05 probability level.

\section{3 盐碱胁迫对花生产量性状的影响}

从表 4 和表 5 可以看出, 盐碱胁迫明显抑制花生荚果 的发育, 从而影响产量, 与对照相比, 22 个品种(系)的单 株产量、百果重、百仁重和小区产量分别降低了 $3.0 \% \sim 42.7 \% 、 3.0 \% \sim 34.7 \% 、 1.7 \% \sim 24.3 \%$ 和 $15.3 \% \sim 53.0 \%$, 其中小区产量受抑制程度更大，鉴定指标在部分基因型 间存在显著差异。6P03、花育 6303、花育 9305、花育 9307 、 花育 9312 和花育 9313 的单株产量、百果重、百仁重受盐 碱胁迫影响较小, 相对小区产量 $>0.7$, 小区产量较高 $\left(>2333 \mathrm{~kg} \mathrm{hm}^{-2}\right)$, 且除花育 9307 的相对百果重和相对百 仁重外，其余品种间的 4 个产量指标均无明显差异，其饱 果期和收获期耐盐碱性较强。

\section{4 花生产量指标与其他耐盐碱指数的相关性分析} 盐碱胁迫下，花生相对单株产量和相对小区产量与 其余 7 个耐盐碱指数间均为正相关关系，但相关程度不同 (表 6)。相对单株产量与相对主茎高、相对侧枝长呈显著 正相关，与相对地上部干重呈极显著正相关; 相对小区产 量与相对成苗率、相对主茎高、相对侧枝长、相对地上部 干重和相对单株产量均呈极显著正相关, 与相对地下部 干重为显著正相关。说明盐碱胁迫对花生单株产量的影响, 主要与结荚期植株地上部发育程度有关, 个体所起作用 较大; 对小区产量的影响, 既与苗期的群体密度有关, 也 与结荚期和饱果期植株个体发育紧密相关。盐碱胁迫对花 生产量的影响是个体和群体协调所致。

表 5 盐碱胁迫下 22 个花生基因型的小区产量及其耐盐碱指数

Table 5 Yield level per plot and tolerance index of 22 peanut genotypes under saline-alkali stress

\begin{tabular}{|c|c|c|c|c|c|}
\hline $\begin{array}{c}\text { 品种(系) } \\
\text { Cultivar (line) }\end{array}$ & $\begin{array}{c}\text { 小区产量 } \\
\text { PY }\left(\mathrm{kg} \mathrm{hm}^{-2}\right)\end{array}$ & $\begin{array}{c}\text { 相对小区产量 } \\
\text { RPY }\end{array}$ & $\begin{array}{c}\text { 品种(系) } \\
\text { Cultivar (line) }\end{array}$ & $\begin{array}{c}\text { 小区产量 } \\
\text { PY }\left(\mathrm{kg} \mathrm{hm}^{-2}\right)\end{array}$ & $\begin{array}{c}\text { 相对小区产量 } \\
\text { RPY }\end{array}$ \\
\hline $6 \mathrm{P} 03$ & $2487 \mathrm{ab}$ & $0.81 \mathrm{a}$ & 花育 9302 Huayu 9302 & $2247 a b$ & $0.627 \mathrm{abcd}$ \\
\hline 6P09 & $2153 \mathrm{ab}$ & $0.59 \mathrm{abcd}$ & 花育 9303 Huayu 9303 & $1647 \mathrm{~b}$ & $0.503 \mathrm{~cd}$ \\
\hline 花育 6301 Huayu 6301 & $2247 \mathrm{ab}$ & $0.783 \mathrm{ab}$ & 花育 9305 Huayu 9305 & $2533 a b$ & $0.717 \mathrm{abcd}$ \\
\hline 花育 6303 Huayu 6303 & $2380 \mathrm{ab}$ & $0.847 \mathrm{a}$ & 花育 9306 Huayu 9306 & $2287 \mathrm{ab}$ & $0.66 \mathrm{abcd}$ \\
\hline 花育 6304 Huayu 6304 & $1687 \mathrm{~b}$ & $0.59 \mathrm{abcd}$ & 花育 9307 Huayu 9307 & $2980 \mathrm{a}$ & $0.813 \mathrm{a}$ \\
\hline 花育 6306 Huayu 6306 & $2000 \mathrm{ab}$ & $0.683 \mathrm{abcd}$ & 花育 9308 Huayu 9308 & $1687 \mathrm{~b}$ & $0.47 \mathrm{~d}$ \\
\hline 花育 6307 Huayu 6307 & $1667 \mathrm{~b}$ & $0.61 \mathrm{abcd}$ & 花育 9309 Huayu 9309 & $2247 a b$ & $0.687 \mathrm{abcd}$ \\
\hline 花育 6312 Huayu 6312 & $1800 \mathrm{~b}$ & $0.657 \mathrm{abcd}$ & 花育 9310 Huayu 9310 & $2267 \mathrm{ab}$ & $0.667 \mathrm{abcd}$ \\
\hline 花育 6314 Huayu 6314 & $2000 \mathrm{ab}$ & $0.713 \mathrm{abcd}$ & 花育 9311 Huayu 9311 & $2180 \mathrm{ab}$ & $0.713 \mathrm{abcd}$ \\
\hline 花育 71 Huayu 71 & $2133 \mathrm{ab}$ & $0.583 \mathrm{abcd}$ & 花育 9312 Huayu 9312 & $2713 a b$ & $0.78 \mathrm{abc}$ \\
\hline 花育 9301 Huayu 9301 & $1780 \mathrm{~b}$ & $0.523 \mathrm{bcd}$ & 花育 9313 Huayu 9313 & $2600 a b$ & $0.83 \mathrm{a}$ \\
\hline
\end{tabular}

同列不同小写字母表示在 0.05 水平上差异显著。

PY: plot yield; RPY: relative plot yield. Values followed by different lowercase letters in the same column indicate significant difference among cultivars at the 0.05 probability level. 
表 6 盐碱胁迫下花生产量指标与其他耐盐碱指数相关性分析

Table 6 Correlative analysis between yield index and other tolerance indexes under saline-alkali stress

\begin{tabular}{|c|c|c|c|}
\hline $\begin{array}{c}\text { 生育时期 } \\
\text { Growth stage }\end{array}$ & $\begin{array}{l}\text { 农艺性状指标 } \\
\text { Tolerance index }\end{array}$ & $\begin{array}{c}\text { 相对单株产量 } \\
\text { RYP }\end{array}$ & $\begin{array}{c}\text { 相对小区产量 } \\
\text { RPY }\end{array}$ \\
\hline 苗期 Seedling stage & RSR & 0.171 & $0.673^{* *}$ \\
\hline \multirow[t]{4}{*}{ 结荚期 Pod-setting stage } & RMSH & $0.451^{*}$ & $0.702^{* *}$ \\
\hline & RBL & $0.512^{*}$ & $0.550^{* *}$ \\
\hline & RRDW & $0.576^{* *}$ & $0.743^{* *}$ \\
\hline & RSDW & 0.412 & $0.538^{*}$ \\
\hline \multirow[t]{3}{*}{ 饱果期 Pod-filling stage } & RYP & 1.000 & $0.594^{* *}$ \\
\hline & 100-RPW & 0.393 & 0.271 \\
\hline & 100-RSW & 0.302 & 0.265 \\
\hline
\end{tabular}

RSR: 相对成苗率; RMSH: 相对主茎高; RBL: 相对侧枝长; RSDW：相对地上部干重; RRDW：相对地下部干重; 100-RPW：相对百果 重; 100-RSW：相对百仁重。“表示 0.05 水平差异显著; ${ }^{* *}$ 表示 0.01 水平差异显著。

RSR: relative seedling rate; RMSH: relative main stem height; RBL: relative branch length; RSDW: relative shoot dry weight; RRDW: relative root dry weight; RYP: relative yield per pant; 100-RPW: relative 100-pod weight; 100-RSW: relative 100-seed weight. RPY: relative plot yield. ${ }^{*}$ and ${ }^{* *}$ indicate significant difference at the 0.05 and 0.01 probability level, respectively.

\section{5 不同花生品种耐盐碱性的综合评价}

以上分析可知, 分别以 RSR、RMSH、RRDW、RYP 等为依据的种质耐盐碱性排序并不一致，因此任一单 项耐盐碱指数都不能全面、有效地评价不同花生品种的 耐盐碱性，必须进行综合考察。将全生育期 9 个耐盐碱 指数值标准化, 以此为变量对 22 个供试材料进行聚类 分析(图 2)。由图 2 可知, 在 $\lambda=10$ 处将全部材料分为 4 级, 其中第 I 级为高度耐盐碱材料, 包括 $6 \mathrm{P} 03$ 、花育 9305、花育 6303、花育 9307、花育 9313、花育 9312
和花育 9310 等 6 个大果品种和 1 个小果品种, 占总数 的 $31.8 \%$; 第 II 级为较耐盐碱材料，有花育 6306 、花育 9311 、花育 6314 等 11 个, 占总数的 $50 \%$; 第 III 级为 敏感型材料, 包括花育 9303、花育 9306 和花育 9311 共 3 个, 占总数的 $13.6 \%$; 第 IV 级为高度敏感型材料, 仅有花育 9301 , 占总数的 $4.5 \%$ 。综合各项指标，篮选 出花育 9312、花育 9307、花育 9313、6P03、花育 9305 和花育 6303 共 6 个品种, 为耐盐碱的高产花生基因型, 可进一步在盐碱地推广示范。

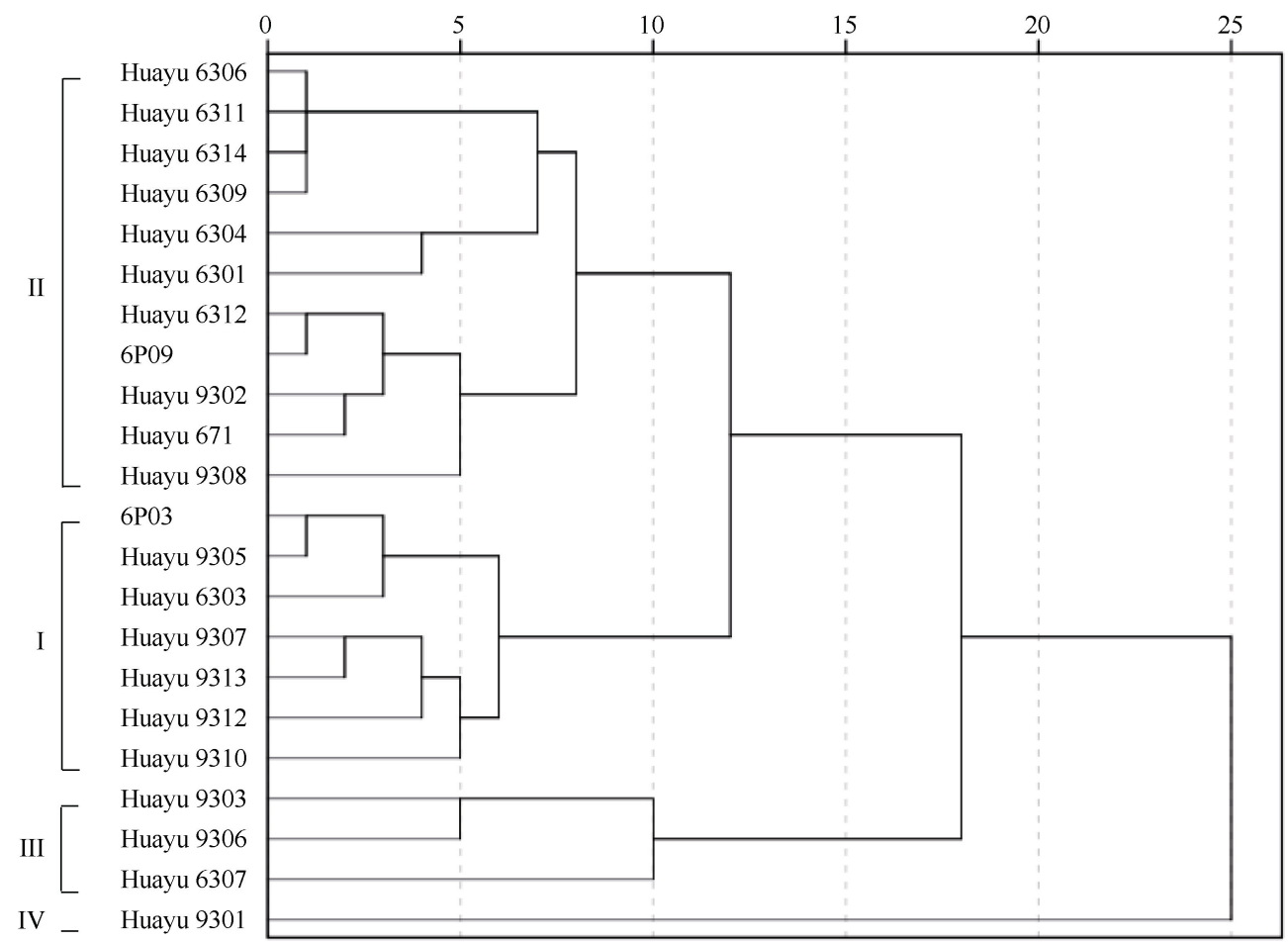

图 2 基于全生育期 9 个耐盐碱指数的供试花生材料的聚类分析

Fig. 2 Cluster analysis of tested peanut genotypes based on nine tolerance indexes in whole growth stage

I、II、III、IV 表示不同耐盐碱级别。

I, II, III, and IV represent different saline-alkali tolerance grade, respectively. 


\section{3 讨论}

\section{1 成苗率是影响盐碱地花生产量的关键因素}

萌发期和苗期是花生对盐碱胁迫最为敏感的时期, 也是决定花生产量的关键时期 ${ }^{[7]}$ 。萌发期耐盐碱性决定了 种子的出苗率, 但出苗的花生并不一定长大结果, 会受制 于其苗期的耐盐碱能力。本研究中, 盐碱胁迫下花生出苗 时间延长, 10 20 d 均有破土。各基因型从出苗至 4 片真叶 期均有不同程度的枯死率，为 $10 \%$ 30\%, 其最终的成苗 率在不同基因型间存在较大差异, 这与盐碱地进行的棉

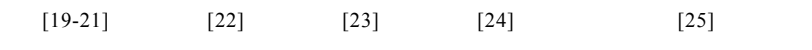
究结果一致。22 个花生基因型中有 13 个相对成苗率低于 0.75 , 其中花育 9303 和花育 9308 的相对成苗率甚至约为 0.5 ; 只有 6 个基因型的相对成苗率在 $0.8 \sim 0.9$ 之间。成苗 率最终成为影响盐碱地花生产量的重要因素, 二者呈极 显著正相关。如本试验中的花育 9301 和花育 9308 , 相对 成苗率最低, 小区产量也最低; 而相对成苗率最高的花育 9307，其小区产量也最高。

\section{2 盐碱胁迫明显抑制花生生长发育及产量形成}

结荚期是花生营养生长最为旺盛的时期, 在持续的 $2.25 \%$ 盐碱胁迫下, 14 个品种(系)的主茎高和侧枝长、6个 品种(系)的相对地上部干重与对照无显著差异, 其中的 $34.8 \%$ 甚至高于对照, 其原因除了与花生品种自身遗传特 性有关外, 可能还与盐碱胁迫下成苗率降低, 株距、行间 距变大, 群体通风透气性改善有关 ${ }^{[26-27]}$ 。饱果期是花生产 量形成的关键时期, 盐碱胁迫明显降低花生的百果重、百 仁重和单株产量, 如花育 6301、花育 6307、花育 9306 等 7 个品种(系)降低了 $10 \% \sim 42.7 \%$, 与符方平 ${ }^{[12]}$ 的研究结果 一致。水稻 ${ }^{[28]}$ 、糯玉米 ${ }^{[29]}$ 、棉花 ${ }^{[30]}$ 等的单株产量及小区 产量在盐碱胁迫下也会明显降低, 这主要与盐碱化造成 的离子毒害、渗透胁迫和营养吸收不平衡有关 ${ }^{[31]}$, 也可能 是由于盐碱地严重缺磷所致 ${ }^{[32-33]}$ 。花生籽仁中富含脂肪和 蛋白质, 是需磷量较大的作物, 每生产 $100 \mathrm{~kg}$ 荚果一般需 要吸收磷 $\left(\mathrm{P}_{2} \mathrm{O}_{5}\right) \quad 1.0 \sim 1.5 \mathrm{~kg}^{[34-35]}$ 。缺磷抑制了花生根系和 地上部生长发育, 生物量、百果重、单株果数、双仁饱果 数、出苗率等明显降低 ${ }^{[36-37]}$, 严重时会显著减产 ${ }^{[27]}$ 。本研 究中盐碱地的有效磷含量仅约为正常地块的 $1 / 10$, 属于 严重缺磷的土壤类型, 花生的成苗率、农艺性状及产量指 标较正常生长花生均明显偏低。

\section{3 以全生育期的多个性状指标篮选耐盐碱花生品种更} 为可靠

盐碱地种植的花生面临着全生育期的盐碱胁迫, 萌发 期和苗期的耐盐碱性与后期耐盐碱性无明显相关性 ${ }^{[7,38]}$ 。 本研究也证实了上述结论, 如成苗率较高的花育 6307 $(83.0 \%)$ 和花育 $9306(81.0 \%)$, 其营养生长并不旺盛, 主茎 高、侧枝长、地上部干重、地下部干重降低了 $13.7 \%$ 59.7\%, 单株果重和小区产量降低了 $20 \% \sim 39 \%$; 相反, 成苗率较 低的 6P09 (58.7\%)、花育 $9310(62.3 \%)$ 和花育 $9302(59.3 \%)$, 营养生长则很旺盛, 相对单株果重分别为 $0.947 、 0.913$ 和
0.823。因此, 仅在萌发期和苗期筛选耐盐碱花生基因型并 不可靠, 其与根据产量确定的耐盐碱基因型并不相同 ${ }^{[39-40]}$, 耐盐碱胁迫花生品种的篮选要基于全生育期的表现来进 行, 要以多个性状作为评价指标 ${ }^{[41]}$ 。本研究选用了苗期、 结莱期、饱果期和收获期的 9 个指标对 22 个花生基因型 进行了系统评价, 其结果更加可靠, 篮选的耐盐碱花生在 生产上更具应用价值。

\section{4 成苗和壮株是花生盐碱地种植的关键}

刘振兴等 ${ }^{[42]}$ 、金建猛等 ${ }^{[33]}$ 、李绍伟等 ${ }^{[44]}$ 以国家区域 试验结果做灰关联摘分析发现, 正常生长条件下, 百果 重、百仁重、结果枝数、单株结果数、单株产量、结果枝 数等对花生产量的影响较大。有研究表明, 盐碱地土壤易 板结, 渗水性差, 根系难以下扎, 花生养分吸收利用难, 从而影响植株生长发育 ${ }^{[45-46]}$ 。本试验结果显示, 盐碱胁迫 下 15 个花生品种(系)的地上部干重较对照降低 10\% 53\%, 相对主茎高、相对侧枝长、相对地上部干重等对单株产量 和小区产量的影响较大; 此外, 相对成苗率、相对单株产 量、相对地下部干重对小区产量的影响也较大, 均达显著 或极显著水平; 相对百果重和相对百仁重与二者的相关 度比较低。因此, 在盐碱地种植花生, 成苗和壮株是关键。 植株健壮、成苗率和单株产量较高、根系发达是篮选耐盐 碱花生品种的主要参考指标。

\section{References}

[1] 欧阳竹, 王泣易, 来剑斌, 王春晶, 刘振, 孙志刚, 侯瑞星. 黄 河三角洲农业高质量发展新模式. 中国科学院院刊, 2020, 35(2): 145-153.

Ou-Yang Z, Wang H S, Lai J B, Wang C J, Liu Z, Sun Z G, Hou $\mathrm{R} X$. New approach of high-quality agricultural development in the Yellow River Delta. Bull Chin Acad Sci, 2020, 35(2): 145-153 (in Chinese with English abstract).

[2] 贾继增, 高丽锋, 赵光耀, 周文彬, 张卫建. 作物基因组学与 作物科学革命. 中国农业科学, 2015, 48: 3316-3332.

Jia J Z, Gao L F, Zhao G Y, Zhou W B, Zhang W J. Crop genomics and crop science revolutions. Sci Agric Sin, 2015, 48: 3316-3332 (in Chinese with English abstract).

[3] 刘永惠, 沈一, 陈志德, 王州飞, 颜伟. 不同花生品种(系)萌发 期耐盐性的鉴定与评价. 中国油料作物学报, 2012, 34: 168-173.

Liu Y H, Shen Y, Chen Z D, Wang Z F, Yan W. Identification of salt tolerance in peanut varieties/lines at the germination stage. Chin J Oil Crop Sci, 2012, 34: 168-173 (in Chinese with English abstract).

[4] 慈敦伟, 戴良香, 宋文武, 张智猛. 花生萌发至苗期耐盐胁迫 的基因型差异. 植物生态学报, 2013, 37: 1018-1027.

Ci D W, Dai L X, Song W W, Zhang Z M. Genotypic differences in salt tolerance from germination to seedling stage in peanut. Chin J Plant Ecol, 2013, 37: 1018-1027 (in Chinese with English abstract).

[5] 郭峰, 万书波, 李新国, 徐平丽, 孟静静. $\mathrm{NaCl}$ 胁迫对花生种 子萌发的影响. 干旱地区农业研究, 2010, 28(3): 177-181.

Guo F, Wan S B, Li X G, Xu P L, Meng J J. Effect of NaCl stress 
on seed germination in peanut. Agric Res Arid Area, 2010, 28(3): 177-181 (in Chinese with English abstract).

[6] 沈一, 刘永惠, 陈志德, 颜伟, 栾玉柱. 花生幼苗期耐盐品种 的篮选与评价. 花生学报, 2012, 41(1): 10-15.

Shen Y, Liu Y H, Chen Z D, Yan W, Luan Y Z. Selection and evaluation of peanut varieties based on seedling salt tolerance. J Peanut Sci, 2012, 41(1): 10-15 (in Chinese with English abstract).

[7] 吴兰荣, 陈静, 许婷婷, 苗华荣, 胡文广, 禹山林. 花生全生 育期耐盐鉴定研究. 花生学报, 2005, 34(1): 20-24.

Wu L R, Chen J, Xu T T, Miao H R, Hu W G, Yu S L. Identification of salt tolerance in peanut growth duration. $J$ Peanut Sci, 2005, 34(1): 20-24(in Chinese with English abstract).

[8] Singh A L, Hariprassana K, Solanity R M. Screening and selection of groundnut genotypes for tolerance of soil salinity. Aust $J$ Crop Sci, 2008, 1: 69-77.

[9] Singh A L, Hariprasanna K, Chaudhari V, Gor H K, Chikani B M. Identification of groundnut cultivars tolerant of soil salinity. $J$ Plant Nutr, 2010, 33: 1761-1776.

[10] Hammad A R, Shaban K A, Tantawy M F. Studies on salinity tolerance of two peanut cultivars in relation to growth, leaf water content, some chemical aspects and yield. J Appl Sci Res, 2010: $1517-1526$.

[11] 胡晓辉, 孙令强, 苗华荣, 石运庆, 陈静. 不同盐浓度对花生 品种耐盐性鉴定指标的影响. 山东农业科学, 2011, (11): 35-37. Hu X H, Sun L Q, Miao H R, Shi Y Q, Chen J. Effects of different $\mathrm{NaCl}$ concentrations on indicators for evaluating salt tolerance of peanut varieties. Shandong Agric Sci, 2011, (11): 35-37 (in Chinese with English abstract).

[12] 符方平. 花生对盐胁迫的适应性及其耐盐性评价. 湖南农业 大学硕士学位论文, 湖南长沙, 2013. pp 35-37.

Fu F P. Adaption to Salt Stress and Salt Tolerance Evaluation. MS Thesis of Hunan Agricultural University, Changsha, Hunan, China, 2013. pp 35-37 (in Chinese with English abstract).

[13] 张智猛, 慈敦伟, 丁红, 宋文武, 符方平, 康涛, 戴良香. 花生 品种耐盐性指标篮选与综合评价. 应用生态学报, 2013, 24: 3487-3494.

Zhang Z M, Ci D W, Ding H, Song W W, Fu F P, Kang T, Dai L $\mathrm{X}$. Indices selection and comprehensive evaluation of salinity tolerance for peanut varieties. Chin J Appl Ecol, 2013, 24: 3487-3494 (in Chinese with English abstract).

[14] 刘倩, 高娅妮, 柳旭, 周文楠, 王佺珍. 混合盐碱胁迫下接种 丛枝菌根真菌和根瘤菌对紫花苜宿生长的影响. 生态学报, 2018, 38: 6143-6155.

Liu Q, Gao Y N, Liu X, Zhou W N, Wang Q Z. Effects of inoculation with arbuscular mycorrhizal fungi and rhizobia on growth of Medicago sativa under saline-alkaline stress. Acta Ecol Sin, 2018, 38: 6143-6155 (in Chinese with English abstract).

[15] 马宏秀, 王开勇, 张开祥, 孟春梅, 安梦洁. 棉粕对盐碱胁迫 下棉花生理及生长补偿效应. 植物学报, 2019, 54: 208-216. Ma H X, Wang K Y, Zhang K X, Meng C M, An M J. Effect of cotton seed meal on cotton physiology and growth compensation under salinity-alkalinity stress. Chin Bull Bot, 2019, 54: 208-216 (in Chinese with English abstract).

[16] 宝力格, 陆平, 史梦莎, 许月, 刘敏轩. 中国高粱地方种质芽 期苗期耐盐性筛选及鉴定. 作物学报, 2020, 46: 734-744.
Bao L G, Lu P, Shi M S, Xu Y, Liu M X. Screening and identification of Chinese sorghum landraces for salt tolerance at germination and seedling stages. Acta Agron Sin, 46: 734-744 (in Chinese with English abstract).

[17] 刘谢香, 常汝镇, 关荣霞, 邱丽娟. 大豆出苗期耐盐性鉴定方 法建立及耐盐种质筛选. 作物学报, 2020, 46: 1-8.

Liu X X, Chang R Z, Guan R X, Qiu L J. Establishment of screening method for salt tolerant soybean at emergence stage and screening of tolerant germplasm. Acta Agron Sin, 2020, 46: 1-8 (in Chinese with English abstract).

[18] 万书波, 王才斌, 吴正锋, 郑永美, 陈殿绪, 郑亚萍, 冯昊, 刘 苹, 郭峰, 赵海军, 单世华, 孙学武. 花生栽培观察记载技术 规范. NY/T 2408-2013.

Wan S B, Wang C B, Wu Z F, Zheng Y M, Chen D X, Zheng Y P, Feng H, Liu P, Guo F, Zhao H J, Shan S H, Sun X W. Observation and record technical specification of peanut in cultivation. NY/T 2408-2013 (in Chinese).

[19] 董合忠. 滨海盐碱地棉花成苗的原理与技术. 应用生态学报, 2012, 23: 566-572.

Dong H Z. Underlying mechanisms and related techniques of stand establishment of cotton on coastal saline-alkali soil. Chin $J$ Appl Ecol, 2012, 23: 566-572 (in Chinese with English abstract).

[20] 戴海芳, 武辉, 阿曼古丽.买买提阿力, 王立红, 麦麦提.阿皮 孜, 张巨松. 不同基因型棉花苗期耐盐性分析及其鉴定指标 篮选. 中国农业科学, 2014, 47: 1290-1300.

Dai H F, Wu H, Amanguli M M T A L, Wang L H, Maimaiti A P Z, Zhang J S. Analysis of salt-tolerance and determination of salt-tolerant evaluation indicators in cotton seedlings of different genotypes. Sci Agric Sin, 2014, 47: 1290-1300 (in Chinese with English abstract).

[21] 严青青, 张巨松, 徐海江, 李星星, 王燕提. 盐碱胁迫对海岛 棉幼苗生物量分配和根系形态的影响. 生态学报, 2019, 39: 7632-7640.

Yan Q Q, Zhang J S, Xu H J, Li X X, Wang Y T. Effects of saline-alkali stress on biomass allocation and root morphology of sea island cotton seedlings. Acta Ecol Sin, 2019, 39: 7632-7640 (in Chinese with English abstract).

[22] 慈敦伟, 张智猛, 丁红, 宋文武, 符方平, 康涛, 戴良香. 花生 苗期耐盐性评价及耐盐指标篮选. 生态学报, 2015, 35: 805-814.

Ci D W, Zhang Z M, Ding H, Song W W, Fu F P, Kang T, Dai L $\mathrm{X}$. Evaluation and selection indices of salinity tolerance in peanut seedling. Acta Ecol Sin, 2015, 35: 805-814 (in Chinese with English abstract).

[23] 朱广龙, 宋成钰, 于林林, 陈许兵, 智文芳, 刘家玮, 焦秀荣, 周桂生. 外源生长调节物质对甜高粱种子萌发过程中盐分胁 迫的缓解效应及其生理机制. 作物学报, 2018, 44: 1713-1724.

Zhu G L, Song C Y, Yu L L, Chen X B, Zhi W F, Liu J W, Jiao X R, Zhou G S. Alleviation effects of exogenous growth regulators on seed germination of sweet sorghum under salt stress and its physiological basis. Acta Agron Sin, 2018, 44: 1713-1724 (in Chinese with English abstract).

[24] 张玉娟, 游均, 刘爱丽, 黎冬华, 于景印, 王燕燕, 周瑢, 宫慧 慧, 张秀荣. 芝麻发芽期耐盐性鉴定方法研究及耐盐候选基 因的挖掘. 中国农业科学, 2018, 51: 2235-2247. 
Zhang Y J, You J, Liu A L, Li D H, Yu J Y, Wang Y Y, Zhou R, Gong H H, Zhang X R. Screening method for salt tolerance in Sesame (Sesamum indicum L.) and identification of candidate salt-tolerant genes. Sci Agric Sin, 2018, 51: 2235-2247 (in Chinese with English abstract).

[25] 管博, 周道玮, 田雨, 杨季云, 肖模昕. 盐碱及变温条件对花 苜宿种子发芽的影响. 中国草地学报, 2010, 32(1): 58-63.

Guan B, Zhou D W, Tian Y, Yang J Y, Xiao M X. Effect of salt-alkali and changing temperature on seed germination of Melissilus ruthenicus. Chin J Grassland, 2010, 32(1): 58-63 (in Chinese with English abstract).

[26] 孙现军, 姜奇彦, 胡正, 张慧媛, 徐长兵, 邸一桓, 韩龙植, 张 辉. 水稻资源全生育期耐盐性鉴定筛选. 作物学报, 2019, 45: 1656-1663.

Sun X J, Jiang Q Y, Hu Z, Zhang H Y, Xu C B, Di Y H, Han L Z, Zhang $\mathrm{H}$. Screening and identification of salt-tolerant rice germplasm in whole growth period. Acta Agron Sin, 2019, 45: 1656-1663 (in Chinese with English abstract).

[27] 万书波. 中国花生栽培学. 上海: 上海科学技术出版社, 2003. pp 298-300.

Wan S B. Peanut Cultivation in China. Shanghai: Shanghai Scientific and Technical Publisher, 2003. pp 298-300 (in Chinese).

[28] 梁银培, 孙健, 索艺宁, 刘化龙, 王敬国, 郑洪亮, 孙晓雪, 邹 德堂. 水稻耐盐性和耐碱性相关性状的 QTL 定位及环境互作 分析. 中国农业科学, 2017, 50: 1747-1762.

Liang Y P, Sun J, Suo Y N, Liu H L, Wang J G, Zheng H L, Sun X X, Zou D T. QTL mapping and QTL $\times$ environment interaction analysis of salt and alkali tolerance-related traits in rice (Oryza sativa L.). Sci Agric Sin, 2017, 50: 1747-1762 (in Chinese with English abstract).

[29] 谭军利, 康跃虎, 窦超银. 干旱区盐碱地覆膜滴灌不同年限对 糯玉米生长和产量的影响。中国农业科学，2013，46: 4957-4967.

Tan J L, Kang Y H, Dou C Y. Effects of different irrigation and cropping years on waxy corn growth and yield using drip irrigation with plastic-film mulching on saline-sodic soils in arid area. Sci Agric Sin, 2013, 46: 4957-4967 (in Chinese with English abstract).

[30] 秦都林, 王双否, 刘艳慧, 聂军军, 赵娜, 毛丽丽, 宋宪亮, 孙 学振. 滨海盐碱地棉花秸秆还田对土壤理化性质及棉花产量 的影响. 作物学报, 2017, 43: 1030-1042.

Qin D L, Wang S L, Liu Y H, Nie J J, Zhao N, Mao L L, Song X L, Sun X Z. Effects of cotton stalk returning on soil physical and chemical properties and cotton yield in coastal saline-alkali soil. Acta Agron Sin, 2017, 43: 1030-1042 (in Chinese with English abstract).

[31] Sun J, Zou D T, Luan F S, Zhao H W, Wang J G, Liu H L, Liu Z L. Dynamic QTL analysis of the $\mathrm{Na}^{+}$content, $\mathrm{K}^{+}$content, and $\mathrm{Na}^{+} / \mathrm{K}^{+}$ratio in rice roots during the field growth under salt stress. Biol Planta, 2014, 58: 689-696.

[32] 罗佳, 候银荣, 程军回, 王宁宁, 陈波浪. 低磷胁迫下不同磷 效率基因型棉花的根系形态特征. 中国农业科学, 2016, 49: 2280-2289.

Luo J, Hou Y Y, Cheng J H, Wang N N, Chen B L. Root morphological characteristics of cotton genotypes with different phosphorus efficiency under phosphorus stress. Sci Agric Sin,
2016, 49: 2280-2289 (in Chinese with English abstract).

[33] 辛承松, 董合忠, 罗振, 唐薇, 张冬梅, 李维江, 孔祥强. 黄河 三角洲盐渍土棉花施用氮、磷、钾肥的效应研究. 作物学报, 2010, 36: 1698-1706.

Xin C S, Dong H Z, Luo Z, Tang W, Zhang D M, Li W J, Kong X Q. Effects of N, P, and $\mathrm{K}$ fertilizer application on cotton grown in saline soil in Yellow River Delta. Acta Agron Sin, 2010, 36: 1698-1706 (in Chinese with English abstract).

[34] Schachtman D P, Reid R J, Ayling S M. Phosphorus uptake by plants: From soil to cell. Plant Physiol, 1998, 116: 447-453.

[35] Rausch C, Bucher M. Molecular mechanisms of phosphate transport in plants. Planta, 2002, 216: 23-37.

[36] 郑亚萍, 信彩云, 王才斌, 孙秀山, 杨伟强, 万书波, 郑永美, 冯昊, 陈殿绪, 孙学武, 吴正锋. 磷肥对花生根系形态、生理 特性及产量的影响. 植物生态学报, 2013, 37: 777-785.

Zheng Y P, Xin C Y, Wang C B, Sun X S, Yang W Q, Wan S B, Zheng Y M, Feng H, Chen D X, Sun X W, Wu Z F. Effects of phosphorus fertilizer on root morphology, physiological characteristics and yield in peanut (Arachis hypogaea L.). Chin J Plant Ecol, 2013, 37: 777-785 (in Chinese with English abstract).

[37] 董晓霞, 魏建林, 杨果, 李彦, 田叶, 管力生, 崔荣宗. 春花生 养分限制因子与缺肥时花生体内氮磷钾的分配研究. 中国农 学通报, 2008, 24(4): 277-281.

Dong X X, Wei J L, Yang G, Li Y, Tian Y, Guan L S, Cui R Z. Studies on limiting nutrient elements of spring peanut and distribution of nitrogen, phosphorus and potassium in different parts when lack of nutrients. Chin Agric Sci Bull, 2008, 24(4): 277-281 (in Chinese with English abstract).

[38] 王传堂, 王秀贞, 吴琪, 唐月异, 孙全喜, 王志伟. 花生新品 种(系)东营盐碱地种植丰产性初步评价. 山东农业科学, 2016, 48(10): 69-73.

Wang C T, Wang X Z, Wu Q, Tang Y Y, Sun Q X, Wang Z W. Preliminary evaluation on yielding ability of new peanut cultivars (lines) planted in saline and alkaline lands in Dongying. Shandong Agric Sci, 2016, 48(10): 69-73 (in Chinese with English abstract).

[39] Azad M A K, Alam M S, Hamid M A. Modification of salt tolerance level in groundnut (Arachis hypogaea L.) through induced mutation. Legume Res, 2013, 36: 224-233.

[40] Singh A L, Hariprasanna K, Chaudhari V. Differential nutrients absorption an important tool for screening and identification of soil salinity tolerant peanut genotypes. Indian J Plant Physiol, 2016, 21: 83-92.

[41] 武辉, 侯丽丽, 周艳飞, 范志超, 石俊毅, 阿丽艳·肉孜, 张巨 松. 不同棉花基因型幼苗耐寒性分析及其鉴定指标篮选. 中 国农业科学, 2012, 45: 1703-1713.

Wu H, Hou L L, Zhou Y F, Fan Z C, Shi J Y, Aliyan R Z, Zhang J $\mathrm{S}$. Analysis of chilling-tolerance and determination of chillingtolerance evaluation indicators in cotton of different genotypes. Sci Agric Sin, 2012, 45: 1703-1713 (in Chinese with English abstract).

[42] 刘振兴, 周桂梅, 刘自华, 孟庆祥, 石春雨. 花生产量与农艺 性状的灰关联摘分析. 中国油料作物学报, 2006, 28: 25-28. Liu Z X, Zhou G M, Liu Z H, Meng Q X, Shi C Y. Grey correlation analysis between peanut yield and agronomic traits. Chin $J$ Oil Crop Sci, 2006, 28: 25-28 (in Chinese with English abstract). 
[43] 金建猛, 谷建中, 刘向阳, 任丽, 范君龙. 花生农艺性状与产 量的灰色关联度分析. 种子科技, 2009, 27(5): 31-33.

Jin J M, Gu J Z, Liu X Y, Ren L, Fan J L. Grey correlation analysis between peanut yield and agronomic traits. Seed Sci Technol, 2009, 27(5): 31-33 (in Chinese with English abstract).

[44] 李绍伟, 李军华, 任丽, 金建猛, 范君龙, 邓丽. 花生产量与 主要农艺性状的灰色关联度分析. 陕西农业科学, 2007, (1): 37-38.

Li S W, Li J H, Ren L, Jin J M, Fan J L, Deng L. Grey correlation analysis between peanut yield and main agronomic traits. Shaanxi J Agric Sci, 2007, (1): 37-38 (in Chinese with English abstract).

[45] Azad M A K, Alaml M S, Hamid M A, Hossain M A. Low $\mathrm{Ca}^{2+} / \mathrm{Na}^{+}$ratio and efficiency of mobilization of $\mathrm{Ca}^{2+}$ from shoot tissues to kernel determine salinity tolerance in groundnut (Arachis hypogaea L.). Legume Res, 2013, 36: 396-405.

[46] Mungala A J, Radhakrishnan T, Dobaria J R. In vitro screening of 123 India peanut cultivars for sodium chloride induced salinity tolerance. World J Agric Sci, 2008, 4: 574-582. 